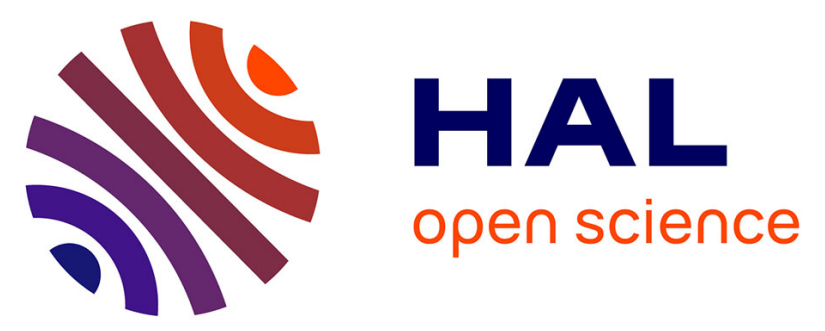

\title{
Modeling the Craftsmen Know-How: A Case Study Using MASK Methodology
}

Imane El Amrani, Abdelmjid Saka, Nada Matta, Taoufik Ouazzani Chahdi

\section{To cite this version:}

Imane El Amrani, Abdelmjid Saka, Nada Matta, Taoufik Ouazzani Chahdi. Modeling the Craftsmen Know-How: A Case Study Using MASK Methodology. 5th IFIP International Workshop on Artificial Intelligence for Knowledge Management (AI4KM), Aug 2017, Melbourne, VIC, Australia. pp.66-83, 10.1007/978-3-030-29904-0_6. hal-02517699

\section{HAL Id: hal-02517699 \\ https://hal.inria.fr/hal-02517699}

Submitted on 24 Mar 2020

HAL is a multi-disciplinary open access archive for the deposit and dissemination of scientific research documents, whether they are published or not. The documents may come from teaching and research institutions in France or abroad, or from public or private research centers.
L'archive ouverte pluridisciplinaire HAL, est destinée au dépôt et à la diffusion de documents scientifiques de niveau recherche, publiés ou non, émanant des établissements d'enseignement et de recherche français ou étrangers, des laboratoires publics ou privés. 


\title{
Modeling the Craftsmen Know-how: a Case Study using MASK Methodology
}

\author{
Imane El Amrani ${ }^{1}$ and Abdelmjid Saka ${ }^{1}$ and Nada Matta ${ }^{2}$ and Taoufik Ouazzani \\ Chahdi ${ }^{1}$ \\ ${ }^{1}$ National School of Applied Sciences of Fez, Quartier Industriel Ain Chkef, Fez, Morocco \\ ${ }^{2}$ University of Technology of Troyes, 12 Rue Marie Curie, 10010 Troyes, France \\ imane.elamrani2@usmba.ac.ma, abdelmjid.saka@usmba.ac.ma, \\ t.ouazzani@ueuromed.org, nada.matta@utt.fr
}

\begin{abstract}
Moroccan handicraft is rich in its know-how and authenticity, but today the informal way of transmitting knowledge loses its effectiveness. The risk of losing this cultural heritage because of competition and globalization challenges is real and its preservation is more necessary than ever. For that purpose, this paper aims to set up a capitalization process using knowledge management methods that are the best suited to be applied to this specific field. Presented here is a methodological framework divided into four big stages that are explained through a case study within the Moroccan zellige handicraft. The approach calls for identifying the most critical and vulnerable know-how and its transcription through a modeling approach. The methods used come from the knowledge management and knowledge engineering domains. We have chosen the MASK method for knowledge modeling and a mix between the "Process" approach and the "Domain" approach for the criticality study. The result is first and foremost a critical knowledge map of the proposed craft; and secondly, a transcription of the knowledge in the form of knowledge models that will compose a business memory currently missing in the handicrafts field.
\end{abstract}

Keywords: Knowledge Engineering, Knowledge modeling, MASK, Moroccan handicraft, Handicrafts, Capitalization.

\section{Introduction}

The Moroccan handicraft constitutes a rich and diversified cultural heritage. An ancestral heritage transmitted from generation to generation and from father to son through observation, imitation and practice. This is a tacit knowledge, rooted in action and routines and therefore difficult to formalize and transmit. A master craftsman acquires expertise derived from years of practice and experience, but he is often unable to describe the scientific rules or the technical principles relating to what he knows. When this transmission, which is inherently informal, deteriorates and loses its effectiveness two critical risks present themselves: i) the vulnerability of this sector 
in relation to a crucial competence, which becomes increasingly rare, and ii) a cultural heritage is lost and the trade disappears. Hence the need to preserve the know-how of craftsmen in order to ensure its transmission and subsequently its sustainability.

To address this need, our study has been carried out with the objective of developing an appropriate and systematic approach based on MASK Method [1] in order to preserve the experiential knowledge of handicraftsmen in the form of a craft book that will be considered as reference in term of preservation of the handicrafts. However, most of the methods from the field of Knowledge Management and Knowledge Engineering have been designed within the formal world of industries and organizations. They require a high level of professionalization on the part of the actors involved in the capitalization process. MASK was chosen as it perfectly matches our objectiv in developping a book of knowledge besides its flexibility and easier ownership and especially its generic character [2] allowing it to adapt to different fields. However, some of its principles do not fit the world of craft and handedness. The crafts industry is governed by the informal in the absence of documentation and a low level of education making it difficult for the artisans to benefit from a formal capitalization process. In the light of this problem, a case study has been carried out to highlight the problems encountered and study the solutions to put in place. The case study is within the Moroccan zellige handicraft. A kind of clay mosaic hand cut in different shapes and colors that are imbricated to give shape to geometric decorations that will serve to cover the walls and floors. This ornamental technique is typical of Maghreb architecture and requires a very skilled and experienced handicraftsmen.

The approach addressed in this paper can be mainly divided into four steps: Building the process model, Identifying the critical knowledge, Capturing knowledge and finally modeling the critical knowledge. Every step is explained through the case study using concrete examples. The first two steps of the process give rise to a critical knowledge map that we have constructed in a simple diagram in order to enrich the book of knowledge. The approach behind building this map, although it's processbased at the beginning, is largely inspired by the "Domain" approach proposed by JL Ermines whose work is more present in the literature and is not lacking in detail and clarity especially when it comes to knowledge criticality assessment and representation. After collecting knowledge through observation and interviewing techniques, comes the last stage of modeling. MASK has been used for this purpose and the difficulties encountered are found more within the interviewing process with the expert craftsmen and the models co-construction principle besides the cultural barriers and reluctance to share.

The organization of this paper is as follows. It starts by a brief description of the state of the art and the study context followed by the presentation of the proposed approach and then its application to the case study within the Moroccan zellige craft. Finally, results are discussed; strengths and weaknesses of the methods used are addressed to conclude the paper. 


\section{Current state of the art}

In a cultural heritage context, the creation of a semantic representation of information and knowledge can be achieved effectively through the use of special diagrams. The most common ones are Ontologies such us the use of the CIDOC CRM template to derive the Architecture Metadata Object Schema for the cataloguing of architectural heritage $[3,4]$ or the traditional Malaya Textile knowledge model [5] or the ontologybased model developed within the conservation of the 6th-century San Saba oratory in Rome [4]. Others are using OWL ontologies, as in the case of Indian classical dance for the developpement of a repository to preserve this intangible heritage [6]. However, these approaches are too domain-specific, especially adapted to the field of architectural heritage conservation during investigation activities and are therefore conceived for the design of an information technology system which can manage the big amount of data and information or a knowledge-based system (KBS) to reproduce inference mechanisms and build intelligent systems to assist with problem solving. The application within the handicraft domain is still lacking. Vito et al [7] state that only 5 per cent of the total contributions analyzed in their literature review are focused on research within arts and craft organizations, while the big amount of contributions are dealing with organizations and technological firms in particular. Our goal is to capture the knowledge of the handicraftsmen using a modeling approach to produce models that are easily appropriable and direclty exploitable to form a book of knowledge of the craft field.

A particular study has drawn our attention because it has many similarities with our case study in the way that it tends to formalize the tacit knowledge and operational know-how of the master craftsmen of Calabria in Italy [8]; The methodology used for acquiring and formalizing this knowledge is the CommonKADS standard as the ultimate goal is to develop a searchable and questionable expert system which will represent the cognitive process of experts in that craft sector. However, this method is located in a symbolic level and therfore use an adapted programming language rather than the knowledge level to which we limit ourselves in this paper.

Giving all the reasons mentioned above, MASK methodology [9] appeared to be the best suited to our case and this because of tree main reasons: 1) The knowledge representation format is based on a graphic modeling instead of a programming language, which makes it easy to build and read; 2) It makes it possible to constitute a business memory (book of knowledge) directly exploitable; 3) The interfering with the knowledge (the knowledge level) rather than the system (the symbolic level).

MASK method (Method for Analyzing and Structuring Knowledge), which used to be called MKSM (Method for Knowledge System Management, was invented at the CEA by the mathematician Jean-Louis Ermine [10]. It was used at the beginning to capitalize the knowledge of researchers approaching retirement in three particular areas: the nuclear tests, the fast neutrons and the laser enrichment of uranium [10]. It has been then extended to diferent sectors such as the textile industry and many other fields, namely the automotive industry such as the European giant Renault [11]. The goal of this method is to formalize knowledge from three perspectives that gave rise to six knowledge models [12]: 
- A contextual point of view [12] giving rise to two models: the so-called "phenomenon models" where we seek to identify the phenomena underlying the knowledge and the "activity" model that is used to model the activities of the organization in which knowledge flows.

- A semantic point of view [12] giving rise to two other models: a so-called "task" (or "know-how") model which is a representation of the strategy or the expert reasoning used to solve a problem, and a "concept" model that represents the static aspect of knowledge.

- An evolutionary point of view [12] giving rise to the "historical" and "lineage" models which describe the evolution, first in its context, then in the sense (the lineages).

These models are developed during interviews with knowledge holders. They constitute a structured synthesis of knowledge on a given field called "Book of Knowledge" which is a kind of "business encyclopedia" [12]. It represents the final result of MASK methodology. The transition to a computer application (e.g.decision support system, database, etc.) is possible and immediate, using the models thus developed, which are considered to be sufficient and ready to use [12].

\section{Study Context and Issue}

In order to identify the specific issues related to this field, a case study was conducted within the Moroccan zellige craft that has led to identify the main characteristics describing the specificities of this field. The following points summarize the main characteristics of the Moroccan zellige craft:

- The nature of knowledge: an operational knowledge embedded in action, largely tacit and implicit and difficult to formalize.

- Informal learning: the transmission operates through observation and hands on experience; it's handed down from father to son and from master to novice

- Lack of documentation: an ancestral profession, which has been transmitted from generation to generation and from father to son in the family workshops secret without any formalization. Nevertheless, the work of the mathematician Jean Marc Castéra [13] or the architect Paccard [14] are discussing certain aspects of the Moroccan handicraft related to the design and the rules of geometric construction.

- Very poor level of education: most artisans didn't go to school and therefore do not have the necessary prerequisites to perform a formalization work.

- Difficulty in validating or co-constructing the models with the expert craftsmen: this is largely due to the lack of basic schooling; the majority of craftsmen have not attended school except of some privileged ones whom we have sometimes had the chance to meet.

\section{Methodological Framework}

The study context described above allowed us to build an appropriate approach to apprehend this case study that we describe in the diagram below (Figure 1): 


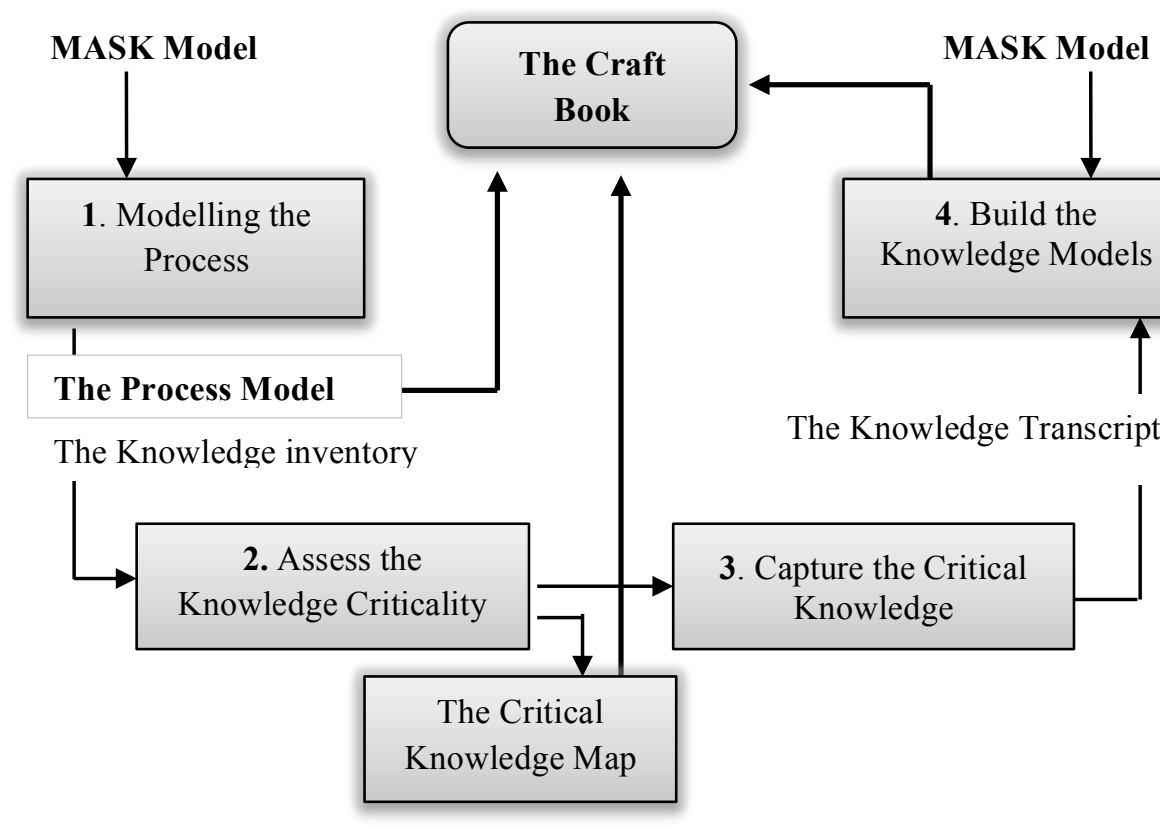

Fig. 1. The methodology.

In this section, the authors will describe the approach taken in this paper. Although it is at first glance obvious and generic in the description of its milestones, it has been the object of multiple revisions and corrections in order to adapt to the real context of the study. It is the result of a long observation in the field and several interviews conducted with stakeholders (artisans, regional delegation, trainers).

The first two stages of the process consist in the modeling of the processes followed by the evaluation of the knowledge criticality to produce two outputs: on the one hand a process model which will feed the craft book and on the other hand a critical knowledge map. The starting point of the methodology was initially the mapping of the critical knowledge in order to focus the capitalization effort on the most critical and vulnerable knowledge before moving on to the modeling process. However, the methods of knowledge mapping that we have studied in the literature, namely GAMETH Methodology [15] and M3C Methods [16] can't be systematically applied to our case study, an adaptation was necessary and led to a mix of the two approaches with a preliminary step of identifying knowledge from processes. This is why the authos have chosen as a starting point the modeling of the processes using MASK method which makes it possible to search the knowledge related to each activity and embedded in actions. This model has a double role; on the one hand it will be the first element, which will compose the trade book, and on the other hand, it 
makes it possible to identify the craft knowledge, which will be evaluated later to study their criticalities.

The M3C method is inspired from the work of the "Knowledge Management club" and is "Domains-oriented" approaches [16]. It calls for identifying knowledge areas based on the company's reference documents such as quality manuals and production documents, which are lacking in this field. The data harvesting technique for the criticality calculation is based on a structured interview with the expert who must assess the criticality level of the knowledge domains. But this very formal interview requires a high level of the interviewees' professionalization. On the other hand, the GAMETH method which is a process-driven and problem-driven approach [15] calls for identifying the essential processes and then the crucial activities in which critical knowledge is located. In the handicraft sector, tacitness is paramount in all of the process stages and a consensus is difficult to reach on identifying the most crucial production stages. Thus, the authors have selected from each of these two methods what best fit their case. From GAMETH, the process-based approach and from M3C the criticality calculation technique which will be explained in more detail in the case study. The authors have also proposed a knowledge map representation (inspired by Ishikawa in a process driven logic) (Figure 7) and an interviewing process for the criticality assessment adapted to the artisans' profile (page 7).

Thus, after deciding what knowledge is most at risk, comes the stage of gathering this knowledge in order to formalize it through a modelling approach (step 3 and 4 of Figure 1). The methods used for the knowledge elicitation are interviews and direct observation of the activity using video/audio recordings. The results of the interviews will be transcribed manually and then analyzed in relation to the different points of view defined by the MASK method (mentioned at the end of section 2). This will make it possible to define the MASK models to be built, namely, the problem-solving model, the concept model, the historical model and the lineage models in addition to the process model already built in the first step.

\section{Implementation of the Methodology within the Moroccan zellige craft}

The case study presented in this paper is within the Moroccan zellige craft. It is a type of handmade mosaic built from simple and basic materials (clay and enamels) using traditional tools that combined with the knobs and precision in the gesture give rise to multicolored geometric creations. The output is zellige panels that are placed on walls and floors and other various architectural elements in order to beautify them and give them more authenticity as shown in the following figure (Figure 2). This craftsmanship can only be achieved through a long experience, practice and repeated observation of the master craftsman's gesture. 


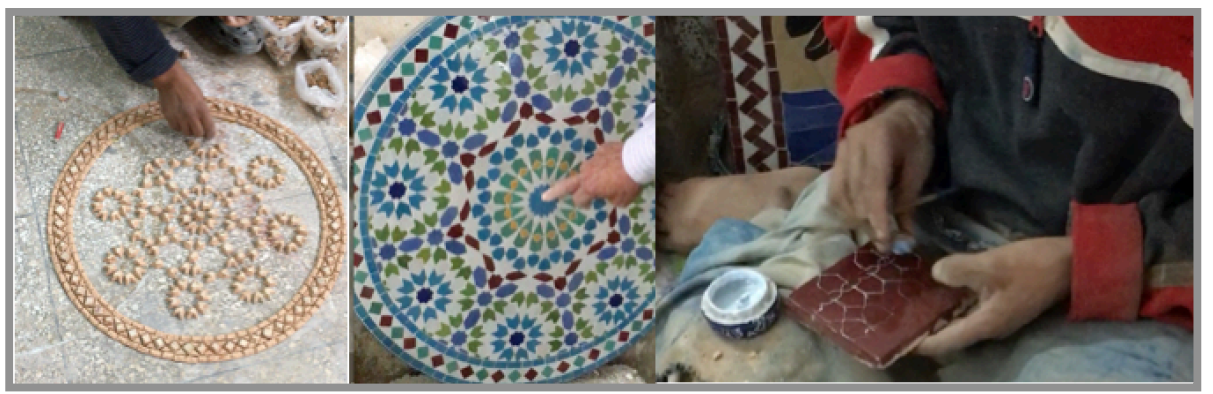

Fig. 2. An overview of the Moroccan zellige craft.

The approach presented above (Figure 1) will thus be validated through this case study. The four steps will be covered one by one in the following with the aim of building a knowledge book for the preservation of this craft.

To conduct this field study, the authors have approached the Regional Delegation of Handicrafts in Fez city who recommended two master craftsmen recognized as experts in the field of zellige craft. It's about the expert craftsman "maâlem Benchekroun" and "maâlem Khalid Saib" who are also trainers at the handicraft training center in Fez. Their workshops were our target to closely observe the activity and to interview the artisans each in his specialty. Ten craftsmen with different levels of expertise were interviewed.

\subsection{Step 1. Modeling the Process}

The authors have chosen to represent the process model using the MASK method (Method of Analysis and Structuring Knowledge) which has been applied in a large number of domains [1] and [2]. This model as shown in Figure 3, makes it possible to associate with each step of the process important elements for the accomplishment of the current activity such as the knowledge, the resources and the actors contributing to these activities. For this purpose, we have proceeded with interviews and videotaping, we have also resorted to some books such as "Arabesque" [13] and "Le Maroc et l'artisanat traditionnel islamique dans l'architecture" [14].

As it was said befor, this process model has a double purpose, on the one hand it constitutes the first model that will compose our business memory which represents the ultimate goal of this work and on the other hand it will allow us to make an exhaustive inventory of the necessary knowledge to building the knowledge map (Figure 4). The identification of the knowledge related to each activity of the process was the subject of a data gathering process based on interviews with the craftsmen. The main question that has been asked is the following: What do you think an artisan should know or be able to do, to accomplish this activity?. We have noticed over the interviews that asking a general question does not encourage the artisan to think and formulate his answer. It is preferable to go from general to specific and be more precise. We can say that we had have found the answer to our question in video recordings and direct observation rather than in the questioning exercise. The answer to our question was more about the tasks and the workflow process. Thus, for our 
case, the know-how related to the activity is assimilated to the tasks / sub-activities carried out.

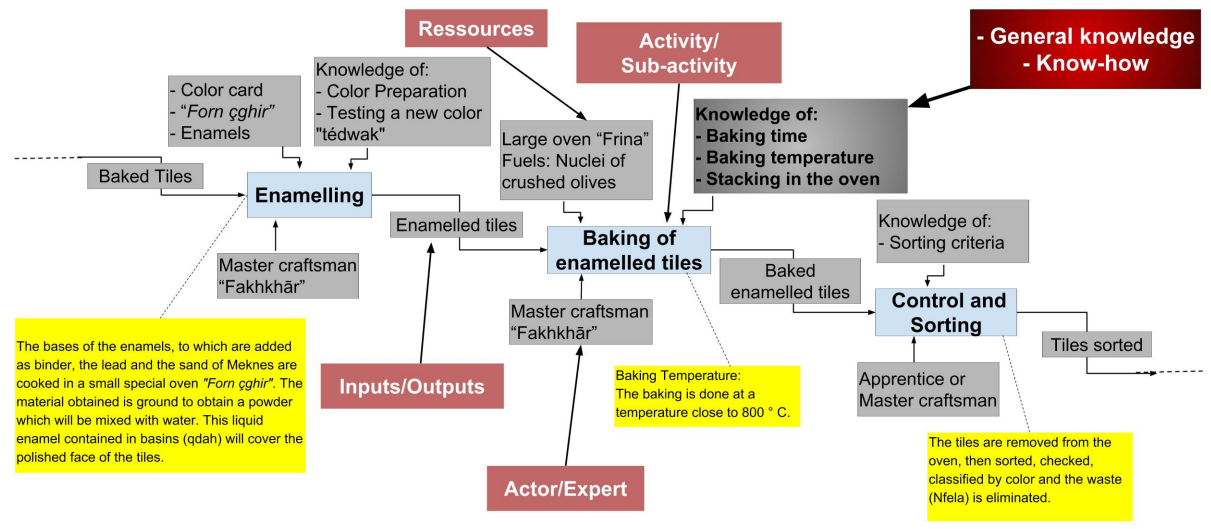

Fig. 3. An overview of the MASK process model

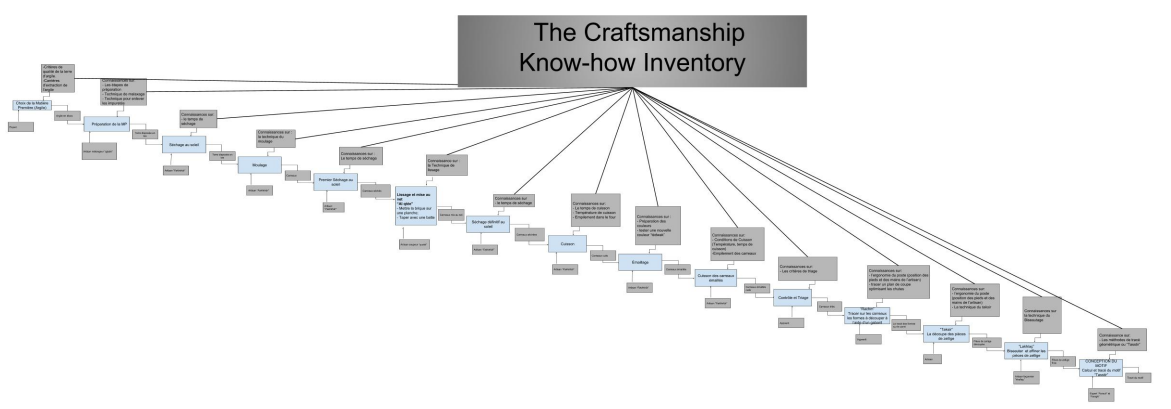

Fig. 4. The knowledge inventory extracted from the process model

\subsection{Step 2. Assessing the Knowledge Criticality}

The first step in assessing the knowledge criticality is the definition of the criticality grid. For this purpose, the authors used the generic evaluation grid called CKF (Critical Knowledge Factors) developed by the Knowledge Management Club [16]. Among the twenty criteria listed, the authors selected a dozen that fit perfectly into the context of the study. Topics covered included the rarity of knowledge holders and difficulties in acquiring and transmitting knowledge. The link with the strategy has also been considered in the criticality assessment. The following table (Table 1) presents the criteria we considered in this study. 
Table 1. The Criticality grid.

\begin{tabular}{|c|l|}
\hline \multicolumn{1}{|c|}{ Themes } & \multicolumn{1}{c|}{ Criteria } \\
\hline Rarity & $\begin{array}{c}\text { 1. Number and availability of holders } \\
\text { 2. Confidentiality }\end{array}$ \\
\hline \multirow{3}{*}{$\begin{array}{c}\text { Difficulty in acquiring } \\
\text { knowledge }\end{array}$} & $\begin{array}{l}\text { 3. Difficulty in identifying sources } \\
\text { 4. Knowledge taciteness }\end{array}$ \\
& $\begin{array}{l}\text { 5. Availability of tangible sources of knowledge } \\
\text { 6. Training time }\end{array}$ \\
\hline Difficulty in using knowledge & 7. Physical hardship \\
& 8. Level of expertise \\
& 10. Difficulty in appropriation \\
& 11. Knowledge of history \\
\hline Strategy & 12. Adequacy with strategy \\
\hline
\end{tabular}

After the definition of the criticality grid, comes the step for the criticality evaluation acording to the criterion already defined. Ermine J-L [17] has proposed a welldeveloped systematic approach for the criticality assessment study in which the levels of each criterion are carefully described and presented to the interviewee. Each assessment of criteria is based on a question. This systematic approach is certainly useful in facilitating the evaluation exercise. Nevertheless, it requires a high level of professionalization and abstraction on the part of the interviewees. For our case we thought of a simplistic approach that best suits our study context and the profile of the evaluators (the artisans) as explained in the following steps.

1. Display the know-how using the craft jargon: the know-how elements defined in the previous step are copied on paper (post-it notes), using the vocabulary commonly used by artisans. These cards are presented to the master craftsman in an order that follows the process sequence.

2. Display only one criterion at a time and ask the espert to rank the knowledge in a criticality decreasing order: The criterion is chosen from the criticality grid, and the expert is asked to classify this knowledge from the most critical to the least critical according to this criterion. For example, for the criterion "Physical hardship", we asked the master craftsman to browse the notes and classify them from the hardest to the least hard by moving the cards on a column of four levels. Sometimes, the ranking is limited to just a few items, which means the criticality of the remaining know-how is negligible compared to those classified and could then be translated by a " 0 " rating.

3. Rate knowledge according to the ranking made by the expert: Each ranking level has a rating from 1 to 4 , " 4 " for the most critical and " 1 " for the least critical as shown in figure 5 . Thus the knowledge classified by the expert in the same Level will have the same notation and so on we will gather the results in a synthetic table. 


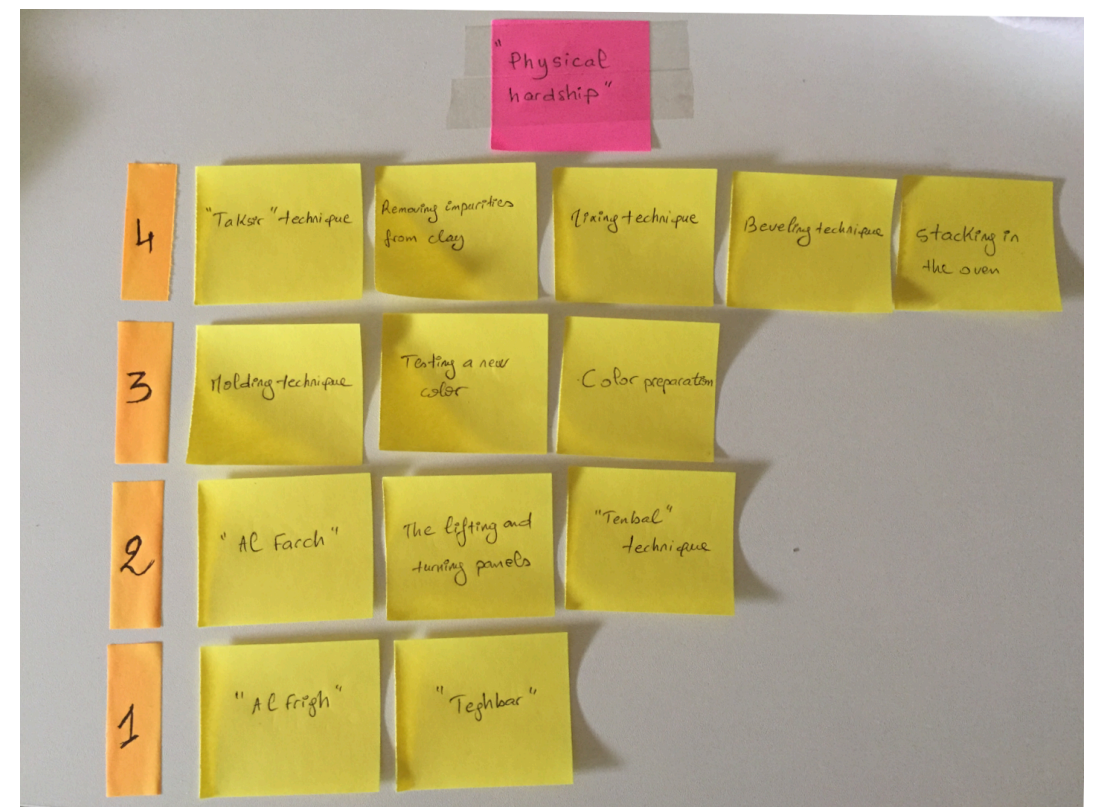

Fig. 5. An example of knowledge classification and ranking.

4. Calculate the knowledge criticality: The criticality of each piece of knowledge is the weighted average of the criticality values for each criterion which is calculated by the following formula where " $\mathrm{M}$ " is the average of criticality values for each criterion [18].

$$
M=\frac{\sum_{i} k i \cdot \text { Vcriterion }}{\sum_{i} k i}
$$

"Vcriterion" is the criticality value evaluated for each know-how and "ki" the weighting coefficient corresponding to criterion $i$ whose value indicates the importance of the criterion as shown in Table 2.

Table 2. The criteria weighting oefficients value.

\begin{tabular}{|c|c|c|}
\hline & Criteria & Weighting coefficient ' $k$ ' \\
\hline C1 & Number and availability of holders & 2 \\
\hline C2 & Confidentiality & 1 \\
\hline C3 & Difficulty in identifying sources & 2 \\
\hline C4 & Knowledge taciteness & 2 \\
\hline C5 & Availability of tangible sources of knowledge & 1 \\
\hline C6 & Training time & 1 \\
\hline C7 & Physical hardship & 2 \\
\hline C8 & Level of expertise & 1 \\
\hline C9 & Complexity & 2 \\
\hline C10 & Difficulty in appropriation & 1 \\
\hline C11 & Knowledge of history & 2 \\
\hline C12 & Adequacy with strategy & 2 \\
\hline
\end{tabular}

The following figure (figure 6) is an extract of the know-how criticality table calculation. On the lines we have the knowledge and on the columns the criticality 
criteria and $\mathrm{M}$ is the criticality average for each knowledge. We have set four criticality levels: 1 for the least critical and 4 for the most critical according to the classification previously performed by expert craftsman.

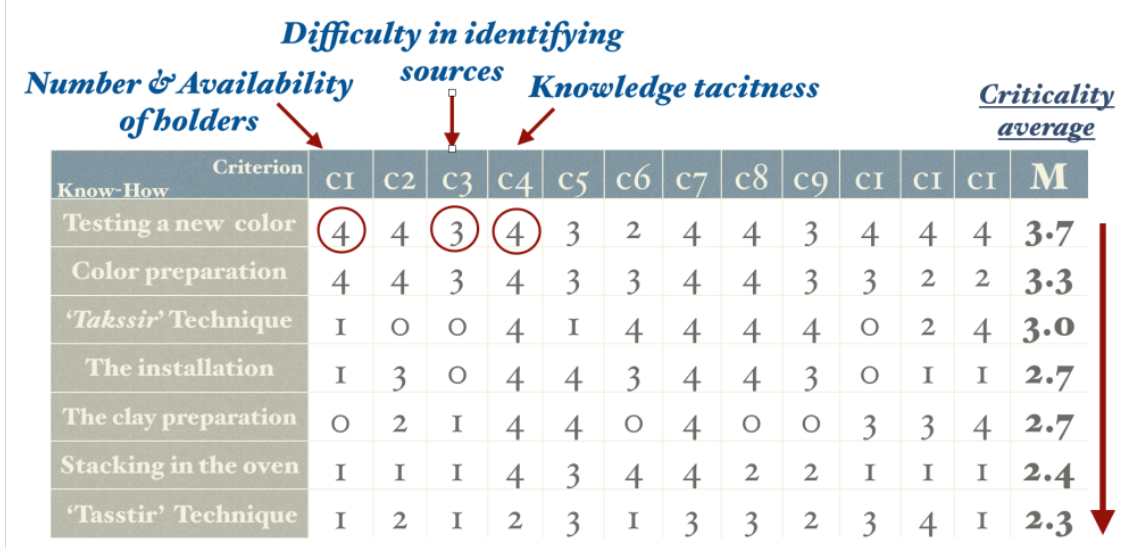

Fig. 6. An extract of the criticality calculation table.

The result of this first part of the study will be synthesized in the form of a critical knowledge map for which the authors have chosen a physical representation inspired from the Ishikawa diagram in a process-driven logic. Thereby the activities in the process model will constitute the map branches and the knowledge linked to each activity will represent the sub-branches of the map as shown in the following diagram (Figure 7).

In order to highlight the criticality level of the knowledge contained on the map, the authors chose three levels of criticality: a high level of criticality which includes $20 \%$ of the knowledge (red color), an average level that consists of $30 \%$ of knowledge (yellow color) and a low criticality level represented by $50 \%$ of the least critical knowledge (green color) (figure 7). 


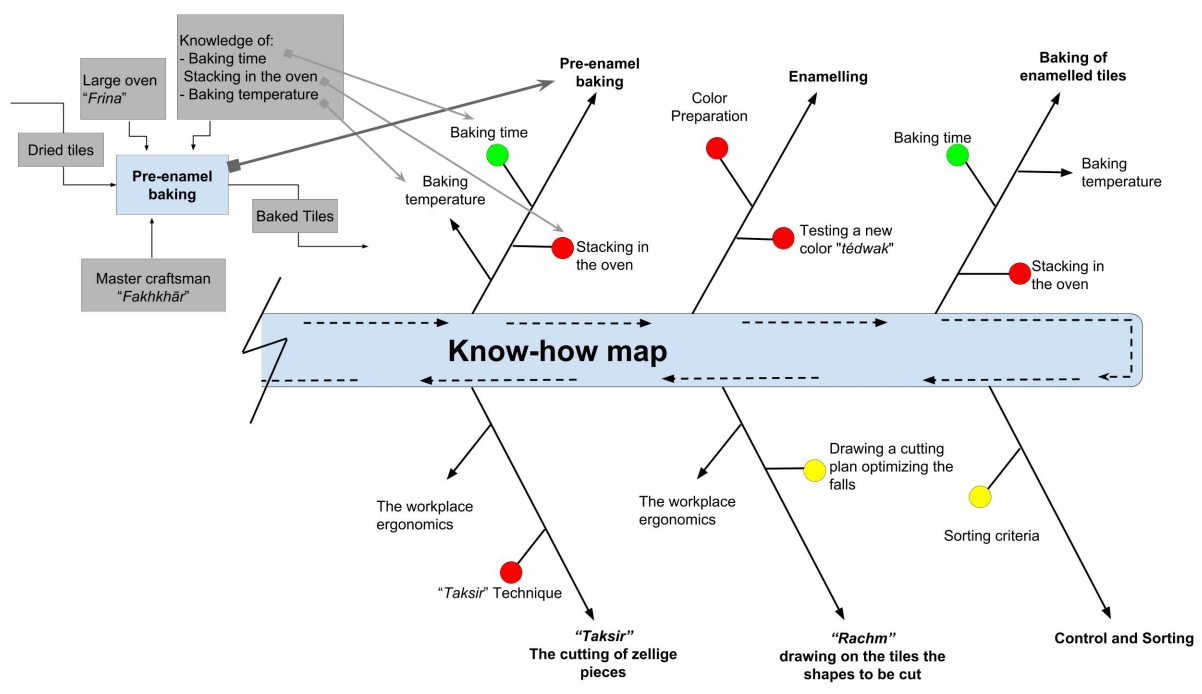

Fig. 7. An extract of the knowledge map

\subsection{Step 3. Capturing the critical knowledge}

Before starting a knowledge elicitation process with expert craftsmen, a preliminary analysis of the criticality table is required (Figure 6). This analysis will make it possible to decide what knowledge can be transcribed in the form of a model. Thus, by crossing on each line the criticality value and on the column the nature of the criterion, it is possible to decide what action to put in place for a knowledge management plan including the knowledge modeling action. For instance, a knowledge which needs to be transcribed as a knowledge model will have a higher criticality according to criteria such as "Number and availability of holders", "Knowledge taciteness" or "Availability of tangible sources of knowledge". We have put some links on the process model to highlight the most critical elements in order to point to the knowledge models we need to build as shown in Figure 8. 


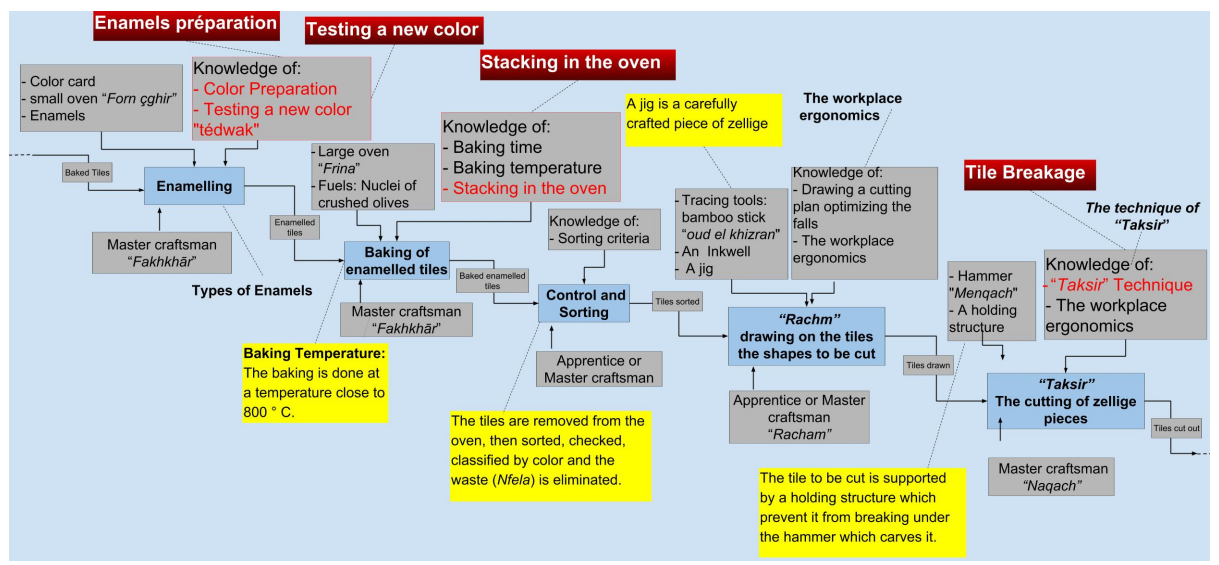

Figure 8 . The critical knowledge highlighted in the process model

Eliciting knowledge from experts.

Many methods have been proposed through several researches addressing the issue of the knowledge acquisition/elicitation techniques. The first research and publications on the knowledge elicitation techniques appeared between 1985 and 2000 in scientific journals of knowledge engineering for the design and development of expert systems [19]. It was not until the 2000s (2000-2011) that a second wave of publications appeared and addressed the subject from a rather managerial point of view in scientific journals such as (Interdisciplinary Journal of Information, Knowledge \& Management, Journal of Management Studies, Knowledge and Process Management, Human Resource Management, Journal of Knowledge Management,) [19]. It is therefore from the 2000s that researchers in the field of knowledge engineering were more interested in knowledge acquisition techniques not only for the development of intelligent systems but also for the knowledge management practices [19]. According to these works [19], the knowledge elicitation process can be divided into several levels according to the degree of knowledge formalization produced. A first level or a primary level includes methods such as: interviewing, observation method, storytelling, round table, brainstorming, role-playing, etc. The secondary level consists of methods that can only be applied after primary methods [19], such as repertory grids, rating, visual concept mapping and card sorting (visual concept mapping and card sorting), Etc.

In the handicraft field, the knowledge is largely operational and the work is totally manual with no formalization. The learning is done through practice and the transfer is completely oral. Thus, an upstream work of research on the field (Process, concepts, artefacts, processes, etc) is necessary. For this purpose, the authors used books, documentaries and other data provided by the Ministry of handicrafts (studies, reports, surveys,). After that, the authors have resorted to prolonged observations of the activity without addressing any questions to the artisans or interrupting him. Subsequently, interviews will be conducted to ask precise and focused questions 
based on the elements of the observation. This elicitation process is summarized in the figure 9.

The questionnaires can be of different types depending on the level of formalization: unstructured, semi-structured and structured interviews. In order to establish a first contact with the craftsman, we created a non-structured questionnaire to understand the key terminology of the field and the techniques used. Then, an additional structured questionnaire was formulated for further information for the elicitation of the MASK knowledge models. Following these interviews, the conversations were transcribed manually after recording in order to be analyzed and then transcribed into MASK models.

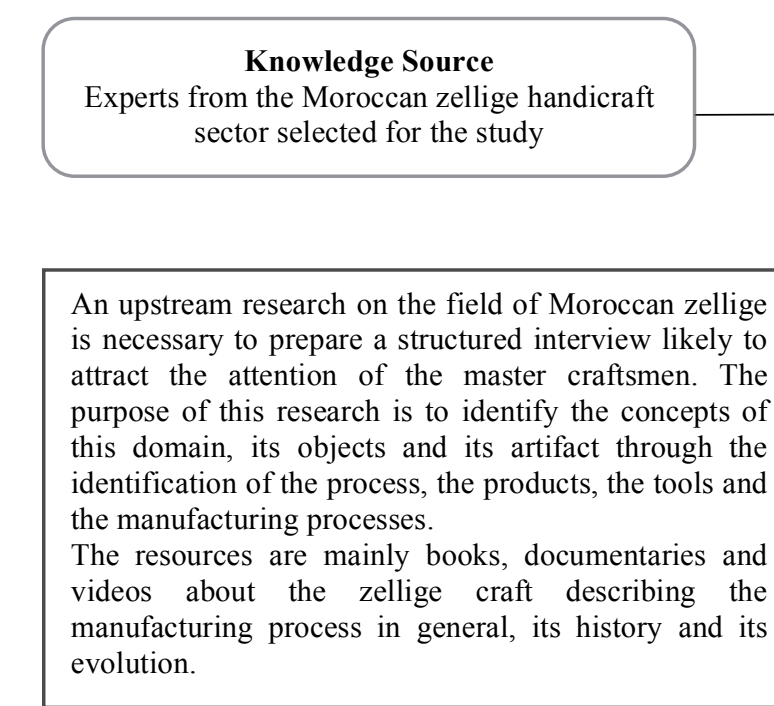

The authors observed closely the work of the master craftsman after explaining to them the purpose of this observation. They used video and audio recordings of the actions carried out by the master craftsman.

The questioning of artisans was not easy at all. The general questions do not arouse any interest of the craftsmen. They need very specific questions. When it comes to problem-solving tasks, they find it difficult to articulate their thought process because of the very manual nature of their activity. Answers were most often assisted by examples and more action-oriented than word-phrasing. It is therefore necessary to ask very specific questions based on concrete examples.

KNOWLEDGE

ELICITATION PROCESS

.

\section{Research on the} Field

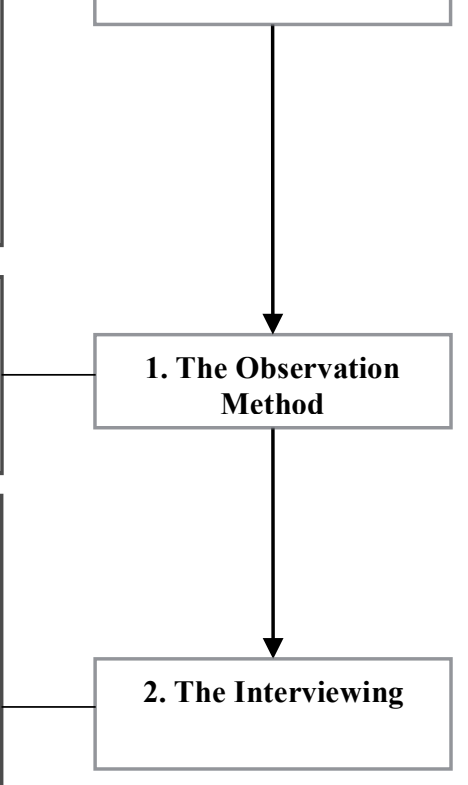

Fig. 9. The knowledge elicitation process 


\subsection{Step 4: Building the knowledge models}

The construction of knowledge models is based on an in-depth analysis of the interviews results with artisans conducted in the previous stage. The analysis technique that has been adopted consists in assigning colors to the answer elements in the transcription text, which refer to a type of MASK model to be constructed. Thus, the light blue color has been attributed to the evoked phenomena (model of the phenomenon), the dark blue color to the processes (process model), the green color has been given to tasks and problem-solving operations (task model / problem solving) and finally the yellow for the concepts.

Among the models mentioned within the text of the interview transcript shown in the figure 10 below, three are presented in this paper, these are:

- The phenomenon model (Figure 11) for the zellige tile "Breakage phenomenon",

- The Task/Problem solving model (Figure 12) for the enameled tiles "Stacking in the oven",

- The Process model (Figure 13) to define "The purification process" of the clay.

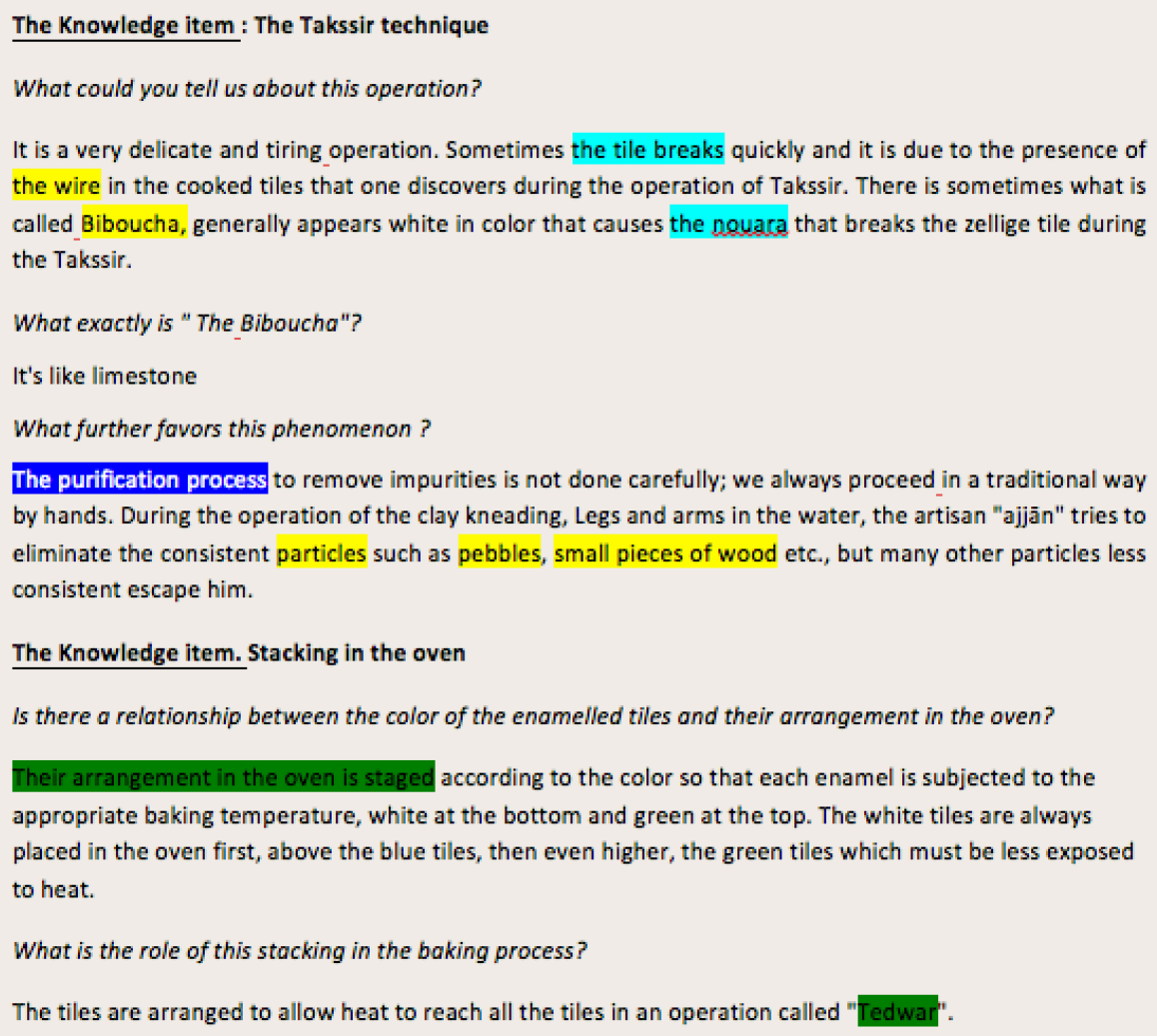

Figure 10. An extract of the interview transcript 


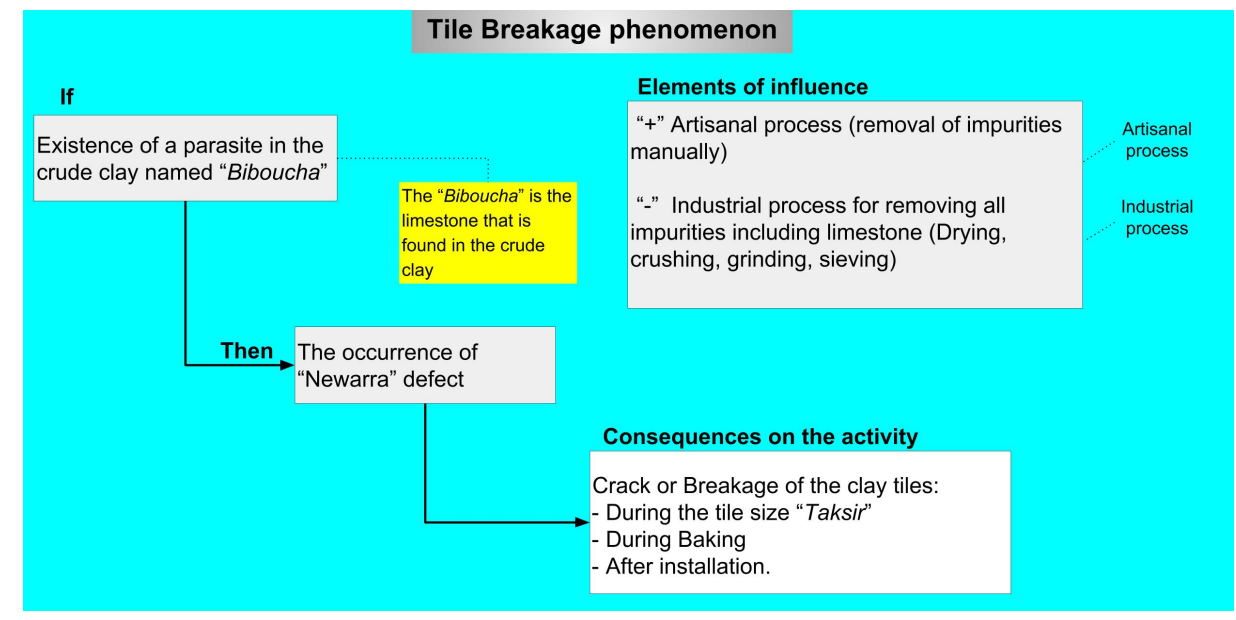

Fig. 11. The "Phenomenon Model" describing the tile breakage phenomenon.

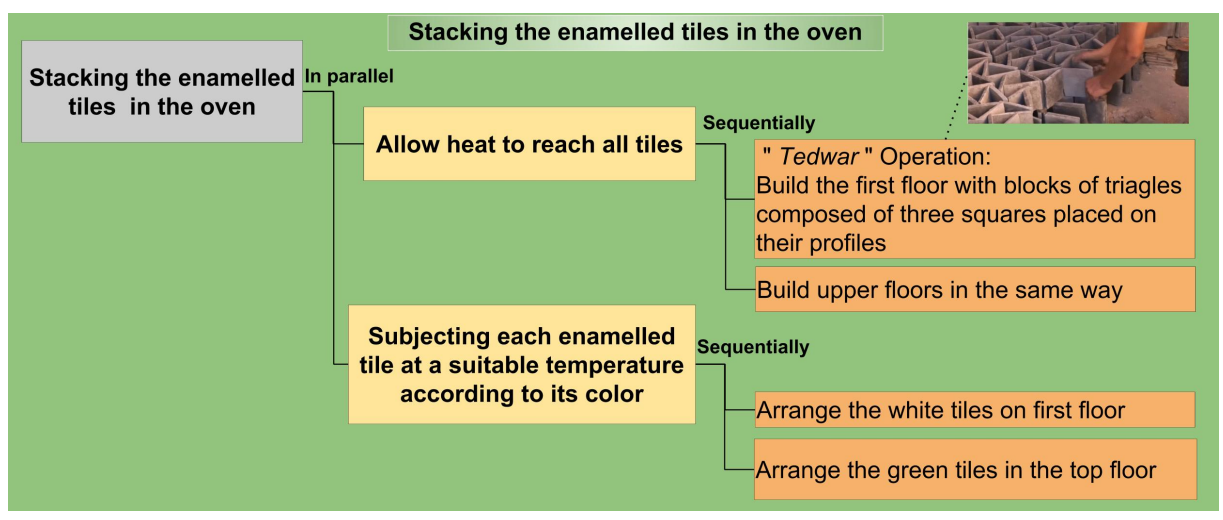

Fig. 12. The "Task/Problem solving" model for the "Stacking in the oven." 


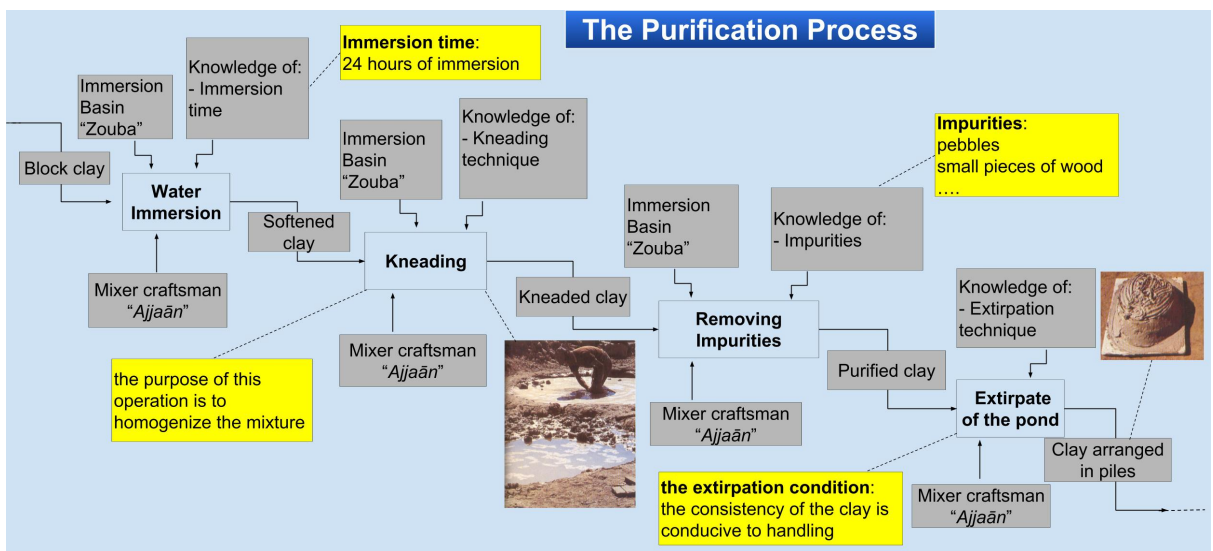

Fig. 13. The Process model for "The Purification Process".

\section{$6 \quad$ Results and Discussion}

The preservation of the Moroccan craftsmanship related knowledge is one of the strategic axis for the Moroccan handicraft preservation program. The study we have conducted in this paper constitutes a first step of this vision. The craft constraints make it difficult to systematically apply the methods that exist in the literature. These are often derived from the industrial world, which is completely different from the world of crafts. However, the application of MASK method has enriched this study and the results are promising. The first phase of the critical knowledge mapping revealed the very tacit aspect of knowledge and the inability of artisans to talk about what they know. Instead, they will talk about what they i.e. their operational knowledge, and this is how the authors agreed that knowledge will be assimilated to the activities and tasks of the process. This was the first proposal of the authors. The criticality evaluation that the master craftsman has to perform craftsmen has also been an issue. The criticality evaluation technique proposed in the M3C method [18] is based on a very formal process, which requires a very high level of abstraction and professionalism. In the absence of this prerequisite, the authors have tested through the case study a very simple technique that adapts to the profile of artisans (see page 7).

Finally, the MASK models were easily appropriate. However, having some knowledge of the trade (technical jargon, techniques and processes) is necessary to apprehend such a project in order to overcome the lack of artisan's professionalization who need to be asked precise and profound questions to stir up their interest. This goes against one of the fundamental principles of knowledge engineering that advises the knowledge engineer to come with zero knowledge so as not to bias the results by an interpretation based on their own understanding and knowledge of the studied field. Another issue in the application of MASK methodology is about the principle of co-construction that the authors were unable to apply due to the artisans' very low education level. Thus, this project has raised many challenges and needs a real 
reflection on how to interview the knowledge holders and involve them more in this process.

\section{Conclusion}

The case study on the Moroccan zellige profession that we carried out and presented in this paper has led up to building an approach for cultural heritage preservation. It constitutes a coherent basis for apprehending a similar project. The one we propose in this article is subject to improvement. It can be further refined and improved. The difficulty lies in the knowledge harvesting technique and the knowledge models validation. The experts interviewed do not meet the required prerequisites to benefit from the formal capitalization process and the co-construction process of the MASK models is not possible. This must be reflected and redesigned according to the knowledge holders' profile. Critical know-how requiring knowledge capitalization constitutes a priority action for the safeguarding and the perpetuation of this profession. Thus we have opted for the knowledge modeling using the MASK methodology in order to build an Electronic Book of Knowledge that will constitute a business memory currently missing.

\section{References}

1. Ermine, J. L.: Capitaliser et partager les connaissances avec la méthode MASK. Hermès, Paris (2001).

2. Matta, N., Ermine, J. L., Aubertin, G., \& Trivin, J. Y.: Knowledge Capitalization with a knowledge engineering approach: the Mask method, proceedings of IJCAI'2001 Workshop on Knowledge Management and Organizational Memory (2001).

3. Agathos, M., \& Kapidakis, S.: A Meta-model Agreement for Architectural Heritage. In Research Conference on Metadata and Semantic Research (pp. 384-395). Springer, Cham (2013, November).

4. Acierno, M., Cursi, S., Simeone, D., Fiorani, D.: Architectural heritage knowledge modelling: An ontology-based framework for conservation process. Journal of Cultural Heritage. 24, 124-133 (2017).

5. Nasir, S. A. M., Noor, N. L. M., \& Razali, S.: The Traditional Malay Textile (TMT) Knowledge Model: Transformation towards Automated Mapping. World Academy of Science, Engineering and Technology, 4, 716-721 (2010).

6. Mallik, A., Chaudhury, S., \& Ghosh, H. (2011). Nrityakosha: Preserving the intangible heritage of Indian classical dance. Journal on Computing and Cultural Heritage (JOCCH), 4(3), 11.

7. Manfredi Latilla, V., Frattini, F., Messeni Petruzzelli, A., \& Berner, M.: Knowledge management, knowledge transfer and organizational performance in the arts and crafts industry: a literature review. Journal of Knowledge Management (2018)

8. Guarasci, R., Cosentino, A., Cardillo, E., Folino, A., \& Taverniti, M.: Gestion et formalisation de la connaissance tacite des maîtres-artisans de la Calabre (Doctoral dissertation, Università della Calabria-Laboratorio di Docuemtazione) (2008) 
9. Matta, N., Ermine, J. L., Aubertin, G., \& Trivin, J. Y.: How to capitalize knowledge with the MASK method. In IJCAI'01 Workshop on Knowledge Management and Organizational Memories, August (Vol. 6) (2001, August).

10. Prax, J. Y.: Le manuel du Knowledge Management: une approche de 2e génération. Paris: Dunod. (2003).

11. Castillo, O., Matta, N., \& Ermine, J. L.: De l'appropriation des connaissances vers l'acquisition des compétences. In 2ème colloque C2EI: Modélisation et pilotage des systèmes de Connaissances et de Compétences dans les Entreprises Industrielles (pp. 1-8) (2004, December).

12. Aries, S., Le Blanc, B., \& Ermine, J. L.: MASK: une méthode d'ingénierie des connaissances pour l'analyse et la structuration des connaissances (2008).

13. Castera, J. M., \& Peuriot, F.: Arabesques: art décoratif au Maroc. Art, Création et Réalisation, ACR (1996).

14. Paccard, A.: Le Maroc et l'artisanat traditionnel islamique dans l'architecture. Atelier 74 (1983).

15. Grundstein, M., \& Rosenthal-Sabroux, C.: Une aide à la décision pour le repérage des connaissances potentiellement cruciales dans un projet de conception: application du cadre directeur GAMETH ${ }^{\circledR}$. Gestion dynamique des connaissances industrielles, 81-106 (2004).

16. Tounkara, T., \& Ermine, J. L.: Méthodes de Cartographie pour l'alignement stratégique de la gestion des connaissances (2008).

17. Ermine, J. L.: Valoriser les connaissances les connaissances critiques d une entreprise (2004).

18. Ermine, J. L., Boughzala, I., \& Tounkara, T.: Critical knowledge map as a decision tool for knowledge transfer actions. Electronic Journal of Knowledge Management, 4(2), 129-140 (2006).

19. Gavrilova, T., \& Andreeva, T.: (Knowledge elicitation techniques in a knowledge management context. Journal of Knowledge Management, 16(4), 523-537 (2012). 